\title{
Melanogenesis Stimulation in Murine B16 Melanoma Cells by Kava (Piper methysticum) Rhizome Extract and Kavalactones
}

\author{
Hideaki Matsuda, ${ }^{*}, a$ Noriko Hirata,${ }^{a}$ Yoshiko Kawaguchi, ${ }^{a}$ Shunsuke Naruto, ${ }^{a}$ \\ Takanobu TAKATA, ${ }^{b}$ Masayoshi Oyama, ${ }^{b}$ Munekazu IInUma, ${ }^{b}$ and Michinori Kubo ${ }^{a, 1)}$ \\ ${ }^{a}$ School of Pharmaceutical Sciences, Kinki University; 3-4-1 Kowakae, Higashiosaka, Osaka 577-8502, Japan: and \\ ${ }^{b}$ Gifu Pharmaceutical University; 5-6-1, Mitahora-higashi, Gifu 502-8585, Japan. \\ Received October 24, 2005; accepted December 14, 2005
}

\begin{abstract}
Melanogenesis stimulation activity of aqueous ethanolic extracts obtained from several different parts of five Piper species, namely Piper longum, P. kadsura, P. methysticum, P. betle, and $P$. cubeba, were examined by using cultured murine B16 melanoma cells. Among them, the extract of $P$. methysticum rhizome (Kava) showed potent stimulatory effect on melanogenesis as well as $P$. nigrum leaf extract. Activity-guided fractionation of Kava extract led to the isolation of two active kavalactones, yangonin (2) and 7,8-epoxyyangonin (5), along with three inactive kavalactones, 5,6-dehydrokawain (1), (+)-kawain (3) and (+)-methysticin (4), and a glucosylsterol, daucosterin (6). 7,8-Epoxyyangonin (5) showed a significant stimulatory effect on melanogenesis in B16 melanoma cells. Yangonin (2) exhibited a weak melanogenesis stimulation activity.
\end{abstract}

Key words Piper methysticum; Kava; 7,8-epoxyyangonin; yangonin; murine B16 melanoma cell; stimulatory effect on melanogenesis

For the development of gray hair prevention agent, we have carried out a screening program to find a potential stimulant of melanogenesis from the natural resources by using cultured murine B16 melanoma cells with theophylline as a reference drug. ${ }^{2,3)}$ It has been reported that theophylline increased both gamma-glutamyl transpeptidase (GGT)- and tyrosinase- reactive cells, as a result, theophylline enhanced pigmentation in cultured murine B16 melanoma cells ${ }^{4)}$ without any effects on cell proliferation. In the previous paper, ${ }^{2)}$ we reported that a methanolic extract from leaves of Piper nigrum (Piperaceae) showed a potent stimulatory effect on melanogenesis and that two lignans, $(-)$-cubebin and (-)3,4-dimethoxy-3,4-desmethylenedioxycubebin, were isolated as active constituent. This observation prompted us to examine melanogenesis stimulation activity in other Piper species. Melanogenesis stimulatory activity of 50\% ethanolic extracts obtained from several different parts of five Piper species, Piper longum, P. kadsura, P. methysticum, $P$. betle, and $P$. cubeba, on murine B16 melanoma cells was assayed. Among them, P. methysticum rhizome extract showed significant stimulatory effect on melanogenesis. The rhizomes of $P$. methysticum have been called Kava (Kava-kava or Kawa) in Oceania, and the South Pacific islanders have been traditionally used the rhizome for the preparation of psychoactive beverage in social and ceremonial events. ${ }^{5)}$ Phytochemicals in P. methysticum have been extensively studied, and a number of kavalactones such as 5,6-dehydrokawain (1), yangonin (2), (+)-kawain (3), (+)-methysticin (4) and 7,8-epoxyyangonin $(\mathbf{5})^{5-8)}$ have been isolated. This paper deals with the screening results of melanogenesis activity of Piper species, and the activity-guided fractionation of $P$. methysticum rhizome extract led to the isolation of active kavalactones, $\mathbf{2}$ and 5 (Fig. 1).

\section{MATERIALS AND METHODS}

Materials Air-dried leaves, stems and rhizomes of $P$. methysticum were purchased at Fiji crude drugs market in
2004. Leaves, stems, rhizomes and roots of P. kadsura were collected at Okinawa, Japan in 2001 and air-dried. Dried whole plant of $P$. betle was purchased at Taiwan crude drugs market in 2004. Fruits of $P$. cubeba were purchased at Indonesia crude drugs market in 2004. Whole plant of $P$. longum was collected at Okinawa, Japan in 2004 and airdried. Air-dried leaves, stems and fruits of P. nigrum were purchased at Thailand crude drugs market in 2001. These samples were identified by one of the authors (M. Kubo). The voucher specimens have been deposited at Kinki University.

Synthetic melanin and $0.4 \mathrm{~m}$ HEPES buffer ( $\mathrm{pH}$ 6.8) were purchased from Sigma-Aldrich Japan (Tokyo, Japan). Dulbecco's modified Eagle medium (D-MEM), Antibiotic-Antimycotic (a mixture of $10000 \mathrm{U} / \mathrm{ml}$ penicillin, $10000 \mu \mathrm{g} / \mathrm{ml}$ streptomycin sulfate, and $25 \mu \mathrm{g} / \mathrm{ml}$ amphotericine B), Dulbecco's phosphate buffered saline $\left(\mathrm{Ca}^{2+}\right.$ - and $\mathrm{Mg}^{2+}$-free, CMF-D-PBS), and trypsin were purchased from Invitrogen Corp. (CA, U.S.A.). Fetal bovine serum (FBS) was purchased from ICN Biomedicals Co. (CA, U.S.A.). Theophylline and the other organic reagents were purchased from Wako Pure Chemical Industries, Ltd. (Osaka, Japan). TetraColor ONE assay kit was purchased from Seikagaku Co. (Tokyo, Japan).

Cell Culture Cultured murine B16 melanoma cell lines (B16F1) for run 1 and run 2 (Table 1) were purchased from Dainippon Pharmaceutical Co., Ltd. (Osaka, Japan) in July, 2001 and May, 2005 respectively. Another murine B16

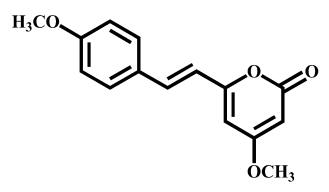

2

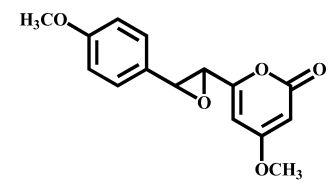

5
Fig. 1. Chemical Structures of Compounds 2 (Yangonin) and $\mathbf{5}(7,8-$ Epoxyyangonin) 
Table 1. Effects of 50\% EtOH Extracts from Piperaceae Plants on Melanin Content in Cultured Murine B16 Melanoma Cells

\begin{tabular}{|c|c|c|c|c|c|c|}
\hline \multirow{2}{*}{ Samples } & \multirow{2}{*}{ Parts } & \multirow{2}{*}{$\begin{array}{l}\text { Conc. } \\
(\mu \mathrm{g} / \mathrm{ml})\end{array}$} & \multicolumn{3}{|c|}{ Melanin content ( $\mu \mathrm{g} /$ well) } & \multirow{2}{*}{$\begin{array}{c}\text { Cell proliferation } \\
(\%)\end{array}$} \\
\hline & & & Intracellular & Extracellular & Total & \\
\hline \multicolumn{7}{|l|}{ Run 1} \\
\hline Control & - & - & $11.0 \pm 0.8$ & $24.8 \pm 1.4$ & 35.8 & $100.0 \pm 0.9$ \\
\hline \multirow{2}{*}{ P. longum } & Whole plant & 1 & $11.8 \pm 0.4$ & $25.0 \pm 0.7$ & 36.8 & $104.0 \pm 1.8$ \\
\hline & & 10 & $9.3 \pm 0.7$ & $19.5 \pm 1.7 *$ & 28.8 & $102.0 \pm 2.5$ \\
\hline \multirow[t]{8}{*}{ P. kadsura } & Leaf & 1 & $11.3 \pm 0.1$ & $23.1 \pm 0.9$ & 34.4 & $98.7 \pm 1.6$ \\
\hline & & 10 & $11.7 \pm 0.4$ & $25.2 \pm 0.7$ & 36.9 & $99.6 \pm 1.4$ \\
\hline & Stem & 1 & $11.7 \pm 0.5$ & $23.6 \pm 0.7$ & 35.3 & $102.9 \pm 0.6$ \\
\hline & & 10 & $11.3 \pm 0.3$ & $25.0 \pm 2.8$ & 36.3 & $104.9 \pm 3.6$ \\
\hline & Root & 1 & $12.7 \pm 0.2 *$ & $25.7 \pm 0.6$ & 38.4 & $104.5 \pm 3.0$ \\
\hline & & 10 & $11.6 \pm 0.5$ & $27.4 \pm 1.0$ & 39.0 & $106.1 \pm 0.9$ \\
\hline & Rhizome & 1 & $11.9 \pm 0.3$ & $27.7 \pm 1.2$ & 39.6 & $104.3 \pm 3.6$ \\
\hline & & 10 & $10.5 \pm 0.2$ & $26.8 \pm 1.3$ & 37.3 & $100.4 \pm 1.6$ \\
\hline \multirow[t]{6}{*}{ P. methysticum } & Leaf & 1 & $9.3 \pm 0.1$ & $25.0 \pm 0.2$ & 34.3 & $101.8 \pm 0.9$ \\
\hline & & 10 & $9.5 \pm 0.5$ & $21.5 \pm 0.5^{*}$ & 31.0 & $106.9 \pm 1.4 *$ \\
\hline & Stem & 1 & $10.7 \pm 0.4$ & $23.8 \pm 1.3$ & 34.5 & $101.7 \pm 2.0$ \\
\hline & & 10 & $12.8 \pm 0.6^{*}$ & $23.3 \pm 0.5$ & 36.1 & $102.2 \pm 1.3$ \\
\hline & Rhizome & 1 & $10.6 \pm 0.8$ & $22.8 \pm 0.4$ & 33.4 & $102.4 \pm 2.9$ \\
\hline & & 10 & $14.0 \pm 0.6^{*}$ & $28.9 \pm 0.4^{*}$ & 42.9 & $108.6 \pm 2.0^{*}$ \\
\hline \multirow[t]{6}{*}{ P. nigrum } & Leaf & 1 & $13.0 \pm 0.3^{*}$ & $39.8 \pm 0.6^{* *}$ & 52.8 & $99.9 \pm 3.4$ \\
\hline & & 10 & $14.9 \pm 0.2 * *$ & $30.9 \pm 0.7 * *$ & 45.8 & $104.0 \pm 2.9$ \\
\hline & Stem & 1 & $11.7 \pm 0.4$ & $37.3 \pm 0.8 * *$ & 49.0 & $98.8 \pm 1.0$ \\
\hline & & 10 & $11.8 \pm 0.4$ & $35.4 \pm 1.2 * *$ & 47.2 & $95.9 \pm 1.5$ \\
\hline & Fruit & 1 & $11.2 \pm 0.5$ & $24.2 \pm 1.8$ & 35.4 & $99.5 \pm 0.6$ \\
\hline & & 10 & $15.5 \pm 1.1^{* *}$ & $21.8 \pm 1.1^{*}$ & 37.3 & $101.6 \pm 0.4$ \\
\hline \multirow{2}{*}{ Theophylline } & & 1 & $12.4 \pm 0.3$ & $42.8 \pm 0.9^{* *}$ & 55.2 & $99.1 \pm 0.8$ \\
\hline & & 10 & $18.7 \pm 0.5^{* *}$ & $61.3 \pm 4.8^{* *}$ & 80.0 & $96.9 \pm 1.2$ \\
\hline \multicolumn{7}{|l|}{ Run 2} \\
\hline Control & - & - & $9.4 \pm 1.4$ & $7.4 \pm 0.5$ & 16.8 & $100.0 \pm 0.7$ \\
\hline \multirow[t]{2}{*}{ P. betle } & Whole plant & 1 & $9.9 \pm 0.8$ & $7.8 \pm 0.4$ & 17.7 & $99.4 \pm 2.4$ \\
\hline & & 10 & $7.7 \pm 0.2$ & $7.8 \pm 0.3$ & 15.5 & $103.2 \pm 2.2$ \\
\hline \multirow[t]{2}{*}{ P. cubeba } & Fruit & 1 & $9.0 \pm 1.0$ & $7.8 \pm 1.0$ & 16.8 & $101.6 \pm 1.0$ \\
\hline & & 10 & $9.9 \pm 0.2$ & $8.1 \pm 0.9$ & 18.0 & $104.6 \pm 0.3$ \\
\hline Theophylline & & 20 & $12.5 \pm 0.7 *$ & $12.0 \pm 0.4 * *$ & 24.5 & $104.8 \pm 1.5$ \\
\hline
\end{tabular}

The murine B16 melanoma cells (passage number 6) cultured in D-MEM (final DMSO conc.; 0.5\%) for $4 \mathrm{~d}$, and each amount of intracellular and extracellular melanin was assayed. The cell lines for run 1 and run 2 are described in Materials and Methods. Total melanin is the sum of intracellular and extracellular melanin amounts. Values are expressed as mean \pm S.E. $(n=3) . \quad * p<0.05, * * p<0.01$, Significantly different from control group.

Table 2. Effects of Compounds 2, 4 and $\mathbf{5}$ on Melanin Content in Cultured Murine B16 Melanoma Cells

\begin{tabular}{|c|c|c|c|c|c|}
\hline \multirow{2}{*}{ Samples } & \multirow{2}{*}{$\begin{array}{l}\text { Conc. } \\
(\mu \mathrm{g} / \mathrm{ml})\end{array}$} & \multicolumn{3}{|c|}{ Melanin content ( $\mu \mathrm{g} /$ well) } & \multirow{2}{*}{$\begin{array}{c}\text { Cell proliferation } \\
(\%)\end{array}$} \\
\hline & & Intracellular & Extracellular & Total & \\
\hline Control & - & $10.6 \pm 0.5$ & $39.4 \pm 3.3$ & 50.0 & $100.0 \pm 1.6$ \\
\hline \multirow[t]{2}{*}{2} & 1 & $13.4 \pm 1.2 * *$ & $36.3 \pm 3.5$ & 49.4 & $100.6 \pm 2.3$ \\
\hline & 10 & $17.3 \pm 0.5 * *$ & $36.2 \pm 1.5$ & 53.5 & $108.2 \pm 1.2 *$ \\
\hline \multirow[t]{2}{*}{4} & 1 & $10.8 \pm 0.6$ & $41.8 \pm 0.7$ & 52.6 & $109.4 \pm 3.4^{*}$ \\
\hline & 10 & $12.4 \pm 0.9$ & $44.6 \pm 0.7$ & 57.0 & $112.2 \pm 2.0 * *$ \\
\hline \multirow[t]{2}{*}{5} & 1 & $16.3 \pm 1.1 * *$ & $51.8 \pm 2.1 * *$ & 68.1 & $107.9 \pm 0.2 * *$ \\
\hline & 10 & $25.4 \pm 0.7 * *$ & $55.3 \pm 3.4 * *$ & 80.7 & $116.9 \pm 2.8 * *$ \\
\hline \multirow[t]{2}{*}{ Theophylline } & 1 & $10.2 \pm 0.3$ & $41.4 \pm 1.4$ & 51.6 & $95.6 \pm 1.2$ \\
\hline & 10 & $21.0 \pm 0.2 * *$ & $89.6 \pm 2.6 * *$ & 110.6 & $94.6 \pm 2.8$ \\
\hline
\end{tabular}

The B16 murine melanoma cells (passage number 6) cultured in D-MEM (final DMSO conc.; 0.5\%) for $4 \mathrm{~d}$, and each amount of intracellular and extracellular melanin was assayed. The lot of cell line is described in Materials and Methods. Total melanin is the sum of intracellular and extracellular melanin amounts. Values are expressed as mean \pm S.E. $(n=3) . \quad * p<0.05, * * p<0.01$, Significantly different from control group.

melanoma cell line purchased in May, 2004 was used for the experiments in Table 2. The B16F1 cell lines were maintained in culture in D-MEM supplemented with $10 \%$ FBS and $1 \%$ Antibiotic-Antimycotic at $37^{\circ} \mathrm{C}$ in a humidified incubator in $5 \% \mathrm{CO}_{2}-95 \%$ air $\left(\mathrm{CO}_{2}\right.$ incubator).

Measurement of Produced Melanin in Cultured B16 Melanoma Cells The amount of melanin in cultured murine B16 melanoma cells was measured according to the method of Hill et al. ${ }^{9)}$ as described in the previous paper. ${ }^{2,3)}$ Test sample and theophylline were dissolved in DMSO/ CMF-D-PBS $(1: 1, \mathrm{v} / \mathrm{v})$, and then diluted with D-MEM to an appropriate concentration. The final concentration of DMSO was $0.1 \%$ or up to $0.5 \%$. In the control group, DMSO/CMF-D-PBS $(1: 1, \mathrm{v} / \mathrm{v})$ solution diluted with $\mathrm{D}$ - 
MEM to $0.1 \%$ or $0.5 \%$ of the final DMSO concentration was used instead of the sample solution. According to the method of Hill et al., ${ }^{9)}$ the amount of melanin retained in the cells (intracellular melanin) and that excreted into the cultured medium (extracellular melanin) were determined separately. The sum amount of melanin was calculated by the addition of both average melanin amounts, and was represented without statistical standard errors.

Assay for Cell Proliferation The cell proliferation of murine B16 melanoma cells was measured according to the method as described in the previous paper. ${ }^{2)}$ Cell proliferation of the treated group was compared with that of the control group.

Statistical Analysis Data points represented the mean values and standard errors. The experimental data were tested for statistical significance using Bonferroni/Dunn's multiple range test method.

Preparation of 50\% Ethanolic Extract Each air-dried and powdered material $(10 \mathrm{~g})$ of Piper plant was extracted with $50 \% \mathrm{EtOH}(100 \mathrm{ml} \times 2$ times $)$ for $2 \mathrm{~h}$ under reflux. Each combined extract was evaporated under reduced pressure, and then lyophilized to give $50 \%$ EtOH extract. Percent yields of each extract were as follows. P. longum L.: whole plant (9.7\%). P. kadsura Онwі: leaves $(25.0 \%)$; stems (13.0\%); rhizomes (10.3\%); roots (9.3\%). P. methysticum Frost: leaves (9.3\%); stems (14.0\%); rhizomes (8.0\%). P. betle L.: whole plant (25.7\%). P. cubeba L.: fruits (16.8\%). P. nigrum L.: leaves (14.0\%); stems (8.0\%); fruits (4.7\%).

Extraction and Isolation of Kavalactones (1-5) and Daucosterin (6) Dry powdered rhizomes $(1 \mathrm{~kg})$ of $P$. methysticum were successively extracted with acetone (101 $\times 2$ times), and $70 \% \mathrm{MeOH}(10 \mathrm{l} \times 2$ times $)$ for $2 \mathrm{~h}$ under reflux. Each combined extract was evaporated under reduced pressure to give an acetone extract $(22.6 \mathrm{~g}, 2.2 \%)$, and a $70 \%$ $\mathrm{MeOH}$ extract $(19 \mathrm{~g}, 1.9 \%)$. Melanogenesis stimulation activity (MSA) of each extract was assayed. The assay results are indicated by MSA $(+)$ or MSA $(-) ;(+)$ : significant effect at $10 \mu \mathrm{g} / \mathrm{ml},(-)$ : no effect at $10 \mu \mathrm{g} / \mathrm{ml}$. The acetone extract was MSA $(+)$, and the $70 \% \mathrm{MeOH}$ extract was MSA $(-)$.

The acetone extract $(22.4 \mathrm{~g})$ was submitted to column chromatography over $780 \mathrm{~g}$ of silica gel (Merck No. 1.07734 silica gel $60,2.3 \times 50 \mathrm{~cm}$ ). Elution with hexane and acetone in increasing portions monitored with TLC [Merck No. 1.05735 silica gel $60 \mathrm{~F}_{254}$, hexane/acetone, $3: 2(\mathrm{v} / \mathrm{v})$, detection; $\mathrm{UV}$ and $10 \% \mathrm{H}_{2} \mathrm{SO}_{4}$ followed with heating] gave 37 fractions of $500 \mathrm{ml}$ each. TLC analysis of the collected fractions allowed us to assemble them into the following 6 fractions (Fr. A to F). MSA of each fraction was assayed, and the assay results are indicated by MSA $(+)$ or MSA $(-) ;(+)$ : significant effect at $10 \mu \mathrm{g} / \mathrm{ml},(-)$ : no effect at $10 \mu \mathrm{g} / \mathrm{ml}$. Fr. A [hexane/acetone $2: 1(\mathrm{v} / \mathrm{v})$, fr. No. 1 to 6 , yield; $5.76 \mathrm{~g}$, MSA (-)], Fr. B [2:1, fr. No. 7-14, $6.00 \mathrm{~g}$, MSA (+)], Fr. C [2:1, fr. No. 15 to $20,8.64$ g, MSA (+)], Fr. D [ $3: 2$, fr. No. 21 to $25,1.03$ g, MSA (-)], Fr. E [1:1, fr. No. 26 to 30, $210 \mathrm{mg}$, MSA (+)], Fr. F [4: 1, fr. No. 31 to 37, $96 \mathrm{mg}$, MSA $(-)$ ]. Crystalline precipitates in Fr. A were collected and recrystallized from EtOAc-hexane to give 5,6-dehydrokawain (1). ${ }^{7,8)}$ [pale yellow needles, mp $136-138^{\circ} \mathrm{C}$ (dec.), $R f$ value on TLC; 0.62 , isolation yield, $0.3 \mathrm{~g}$ ]. Fr. B was recrystallized from EtOAc-hexane to afford yangonin (2) ${ }^{7,8)}$ [pale yellow needles, mp $147-149^{\circ} \mathrm{C}$ (dec.), Rf $\left.0.55,3.46 \mathrm{~g}\right]$. Fr. C was recrystallized from EtOAc-hexane to afford $(+)$-methysticin (4) $)^{7,8)}$ [pale yellow crystalline powder, mp. $127-129^{\circ} \mathrm{C}$, $\left.[\alpha]_{\mathrm{D}}^{25}:+18^{\circ}(c=1.0, \mathrm{MeOH}), R f 0.40,2.56 \mathrm{~g}\right]$ and an additional amount of yangonin (2) $(0.2 \mathrm{~g})$. Monitoring with TLC, Fr. D was purified by repeated column chromatography over silica gel followed by recrystallization to give (+)-kawain $(3)^{7,8)}$ [colorless prisms, mp $98-100^{\circ} \mathrm{C}, R f 0.47,0.6 \mathrm{~g}$ ]. Fr. E was recrystallized from EtOAc-hexane to afford (+)-7,8epoxyyangonin $\left.(\mathbf{5})^{7}\right)$ [pale yellow amorphous powder, $\mathrm{mp}$ $91-93^{\circ} \mathrm{C},[\alpha]_{\mathrm{D}}^{25}+6^{\circ}\left(c=0.5, \mathrm{CHCl}_{3}\right)$, Rf $\left.0.23,180 \mathrm{mg}\right]$. Five known compounds (1-5) were identified by comparison of their physical data (mp, optical rotation, ${ }^{1} \mathrm{H}$ - and ${ }^{13} \mathrm{C}$ NMR) with those of reported data. ${ }^{7,8)}$ Recrystallization of Fr. F from acetone afforded daucosterin [3-( $\beta$-D-glucopyranosyl)stigmasterol $]^{10)}\left[6, \mathrm{mp} 280-283^{\circ} \mathrm{C}\right.$ (dec.), Rf 0.07 , $66 \mathrm{mg}$ ]. Acetylation of $6(10 \mathrm{mg})$ by the usual way gave a tetraacetyldaucosterin $\left(\mathrm{mp} 167-168^{\circ} \mathrm{C}, 11 \mathrm{mg}\right.$ ) which was identified by direct comparison $\left({ }^{1} \mathrm{H}-,{ }^{13} \mathrm{C}-\mathrm{NMR}\right.$, and a mixed fusion) with an authentic sample.

\section{RESULTS AND DISCUSSION}

The stimulatory effect of different Piper plant extracts on melanogenesis in murine B16 melanoma cells and the effect on cell proliferation are shown in Table 1. Additionally, melanogenesis stimulatory activity of the $50 \%$ ethanolic extracts obtained from the leaves, stems and fruits of $P$. nigrum are depicted in Table 1 . The $50 \%$ ethanolic extracts obtained from leaves and stems of $P$. nigrum exhibited potent stimulatory effects on melanogenesis at concentration of 1 and $10 \mu \mathrm{g} / \mathrm{ml}$ as in case of a methanolic leaf extract. ${ }^{2)}$ We previously reported that (-)-cubebin and (-)-3,4-dimethoxy-3,4desmethylenedioxycubebin were active constituents of the leaf of $P$. nigrum ${ }^{2)}$ Both leaf and stem extracts of $P$. nigrum showed similar TLC patterns in which the spots of cubebin and 3,4-dimethoxy-3,4-desmethylenedioxycubebin were obviously detected. Therefore, stimulatory effect of stem extract on melanogenesis could be attributable to cubebin and analogous lignans. The $50 \%$ ethanolic extract of P. nigrum fruit showed melanogenesis stimulation activity. Recently Lin et al. ${ }^{11)}$ reported that a $P$. nigrum fruit extract and piperine showed stimulation of mouse melanogenesis. It was assumed that our results are consistent with their report, and an active constituent is supposed to be piperine which is a major alkaloid amide of the fruits. ${ }^{12)}$ The $50 \%$ ethanolic extract obtained from whole plant of $P$. longum showed decrement of melanin production without any effects on cell proliferation at concentration of $10 \mu \mathrm{g} / \mathrm{ml}$. This result may be in accordance with the report by Min et al. ${ }^{13)}$ in which they described that an alkaloid amide, piperlonguminine isolated from roots and fruits of $P$. longum, showed an inhibitory effect on alphamelanocyte-stimulating hormone ( $\alpha$-MSH)-induced melanogenesis in B16 melanoma cells. Four extracts of several parts of $P$. kadsura showed no effect on both melanogenesis and cell proliferation at concentration of $10 \mu \mathrm{g} / \mathrm{ml}$. The extract of whole plant of $P$. betle showed a tendency to decrease melanin production effect without any effects on cell proliferation at concentration of $10 \mu \mathrm{g} / \mathrm{ml}$. The $P$. cubeba fruit extract had a tendency to increase melanogenesis without any effects on cell proliferation at concentration of $10 \mu \mathrm{g} / \mathrm{ml}$. The 
stimulatory effect on melanogenesis of the $P$. cubeba fruit extract may be attributable to cubebin which is a known constituent in fruits of $P$. cubeba ${ }^{14)}$ as in case of $P$. nigrum leaf extracts. As to $P$. methysticum, leaf extract and stem extract showed a weak decrement of melanin production and a weak stimulatory effect on intracellular melanin production, respectively. The extract of rhizomes of P. methysticum (Kava) exhibited the significant activity with slight increment of cell proliferation at concentration of $10 \mu \mathrm{g} / \mathrm{ml}$. Thus we selected Kava for further examination.

A considerable number of pharmacological studies revealed that Kava and kavalactones showed various biological activities such as antithrombotic, ${ }^{15)}$ spasmolytic, ${ }^{16)}$ neuroprotective ${ }^{17)}$ anxiolytic, ${ }^{18)}$ and anticonvulsive, ${ }^{19}$ ) and TNF- $\alpha$ release inhibitory activities. ${ }^{7)}$ However the melanogenesis stimulatory effect of Kava on B16 melanoma cells has not been reported. To investigate active ingredients in Kava, the rhizome was successively extracted with acetone and $70 \%$ methanol, because kavalactones were efficiently extracted by acetone. $^{20)}$ Melanogenesis stimulation activity of acetone extract was similar to that of $50 \%$ ethanolic extract, whereas $70 \%$ methanolic extract was inactive indicating that the active ingredients are not hydrophilic substances. The activityguided fractionation of Kava acetone extract led to the isolation of five kavalactones, 5,6-dehydrokawain (1), yangonin (2), (+)-kawain (3), (+)-methysticin (4) and 7,8-epoxyyangonin (5) along with a glucosylsterol, daucosterin (6). Although two groups ${ }^{7,8)}$ recently reported the isolation of these kavalactones, $\mathbf{1}-\mathbf{5}$, from Kava, the isolation of $\mathbf{6}$ has not been reported hitherto. On TLC analysis, both the acetone extract and the $50 \%$ ethanolic extract clearly showed the spots of kavalactones, $\mathbf{1}-\mathbf{4}$, whereas the $70 \%$ methanolic extract showed faint spots of these kavalactones compared with those of the acetone extract. These data confirmed the prediction that kavalactones were efficiently extracted by acetone, and may explain slight activity of the $70 \%$ methanolic extract.

Table 2 shows the melanogenesis activities of three kavalactones $(\mathbf{2}, \mathbf{4}$ and $\mathbf{5})$ isolated from the active chromatographic fractions (Fr. B, C and E). Yangonin (2) obtained from Fr. B and $\mathrm{C}$ had a weak stimulatory effect on intracellular melanin production, but (+)-methysticin (4) of Fr. C was inactive. 7,8-Epoxyyangonin (5) obtained from Fr. E dose- dependently increased melanin production with a slight increment of cell proliferation at 1 and $10 \mu \mathrm{g} / \mathrm{ml}$. On the other hand, compounds $\mathbf{1}, \mathbf{3}$, and $\mathbf{6}$, which were isolated from the inactive fractions (Fr. A, D and F) had not any effects (data are not shown). In conclusion, the melanogenesis stimulatory activity of Kava extract is attributable to kavalactones such as $\mathbf{2}$ and $\mathbf{5}$, and it is suggested that Kava extract may be useful as cosmetic stuff for prevention of gray hair.

\section{REFERENCES AND NOTES}

1) Deceased

2) Matsuda H., Kawaguchi Y., Yamazaki M., Hirata N., Naruto S., Asanuma Y., Kaihatsu T., Kubo M., Biol. Pharm. Bull., 27, 16111616 (2004).

3) Matsuda H., Hirata N., Kawaguchi Y., Yamazaki M., Naruto S., Shibano M., Taniguchi M., Baba K., Kubo M., Biol. Pharm. Bull., 28, $1229-1233$ (2005).

4) Hu F., J. Invest. Dermatol., 79, 57-62 (1982).

5) Singh Y. N., J. Ethnopharmcol., 37, 13-45 (1992).

6) Bilia A. R., Scalise L., Bergonzi M. C., Vincieri F. F., J. Chromatogr. $B, \mathbf{8 1 2}, 203-214$ (2004).

7) Hashimoto T., Suganuma M., Fujiki H., Yamada M., Kohno T., Asakawa Y., Phytomedicine, 10, 309-317 (2003).

8) Ranjith H., Dharmaratne W., Nanayakkar N. P. D., Khan I. A., Phytochemistry, 59, 429-433 (2002).

9) Hill S. E., Buffey J., Thody A. J., Oliver I., Bleehen S. S., Mac N. S., Pigment Cell Res., 2, 161-166 (1989).

10) Iwasa J., Naruto S., Yakugaku Zasshi, 85, 469-471 (1965).

11) Lin Z., Hoult J. R. S., Bennett D. C., Raman A., Planta Med., 65, 600-603 (1999).

12) Semler U., Gross G. G., Phytochemistry, 27, 1566-1567 (1988).

13) Min K. R., Kim K. S., Ro J. S., Lee S. H., Kim J. A., Son J. K., Kim Y., Planta Med., 70, 1115-1118 (2004).

14) Prabhu B. R., Mulchandani N. B., Phytochemistry, 24, 329-331 (1985).

15) Gleitz J., Beile A., Wilkens P., Ameri A., Peters T., Planta Med., 63, 27-30 (1997)

16) Seitz U., Ameri A., Pelzer H., Gleitz J., Peters T., Planta Med., 63 303-306 (1997).

17) Backhauss C., Krieglstein J., Eur. J. Pharmacol., 215, 265-269 (1992).

18) Holm E., Staedt U., Heep J., Kortisik C., Behne F., Kaske A., Mennicke I., Arzneim.-Forsch., 41, 673-683 (1991).

19) Gleitz J., Friese J., Beile A., Ameri A., Peters T., Eur. J. Pharmacol., 315, 89-97 (1996).

20) Kuvatova A., Miller D. J., Hawthorne S. B., J. Chromatogr. A, 923, 187-194 (2001). 